\title{
Space group touts 'next steps' for astronauts
}

Tony Reichhardt, Washington

Think more broadly and don't forget international cooperation: that is the message from a veteran group of space scientists and engineers. Together they presented an alternative to NASA's vision for human space exploration at a Paris press conference on 19 July.

Their report, called The Next Steps in Exploring Deep Space, caps a three-year, informal study sponsored by the International Academy of Astronautics. Although it was a volunteer effort with no official government backing, the study reflects the judgement of more than 100 space professionals. These include former NASA space-science chief Wesley Huntress and Bernard Foing, project scientist for SMART-1, Europe's first lunar mission, which was launched last year.

NASA is making plans for a return to the Moon by 2020, to act as a stepping stone to Mars. But the academy suggests two other short-term destinations for astronauts: a Sun-Earth libration point (L2), where future astronomical telescopes will be stationed (see Nature 419, 666; 2002), and near-Earth asteroids. The group recommends that the decision about which goal to tackle first should be based on scientific objectives, and that each successive step should require only one major technology to be developed, partly to lower costs.

The authors call their study"an example of what could be done, not a prescription of what will be done". Yet they clearly intend to broad-

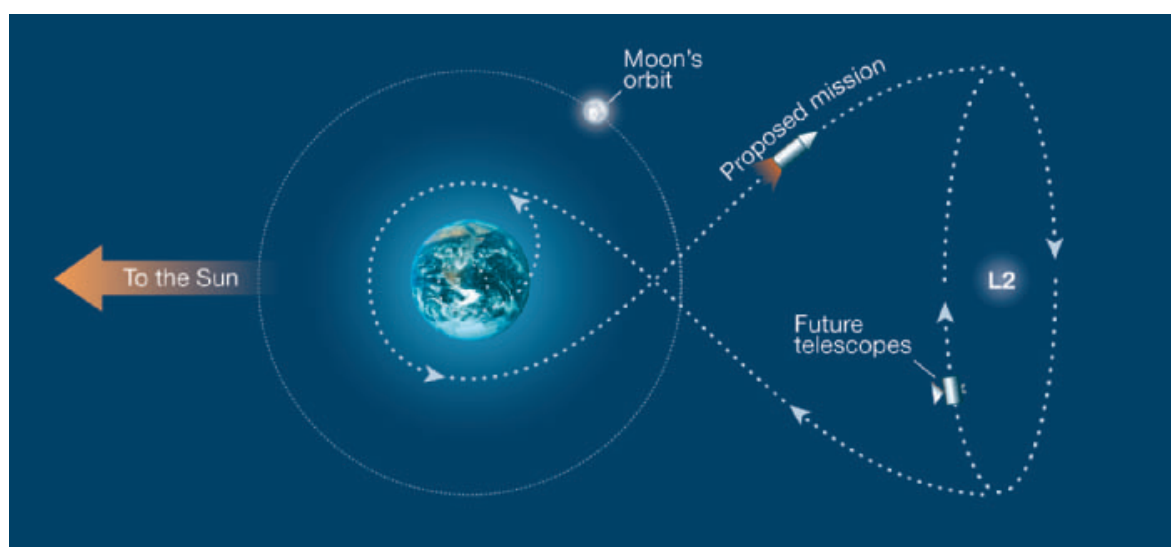

Over the Moon: some say the Sun-Earth libration point L2 is a good target for human missions.

en the 'where next?' debate beyond what some feel is too narrow a focus on the Moon.

The construction and maintenance of astronomical facilities at L2 (see above, not to scale) may provide a good rationale for a programme of human exploration beyond low-Earth orbit, the study's authors write. Astronauts could also be sent to explore asteroids - collecting data to aid in protecting the Earth from possible future collisions.

Huntress, now director of the Carnegie Institution of Washington's Geophysical Laboratory and the study's leader, says its recommendations are in line with President George W. Bush's directive to send humans beyond Earth orbit. But the committee adds that its alternative priorities for space exploration make more economic sense. Making L2 - a point in space four times farther away than the Moon - an early goal for astronauts would defer the cost of a lunar lander and base until after a deep-space vehicle is proven, for example.

The academy places stronger emphasis on the possibility of international cooperation than did a recent US presidential commission. So far, international discussion of Bush's Moon-Mars programme has produced only polite interest. The European Space Agency is conducting its own study of possibilities for human space exploration, but this is not expected to be finalized until next year.

\section{Britain decides 'open access' is still an open issue}

\section{Declan Butler}

Can journals function if authors, instead of readers, carry the cost of publication? An inquiry by the UK House of Commons Science and Technology Committee concluded this week that we will just have to wait and see. After five months of investigating access to journals in science, technology and medicine, the committee has reported that the concept of 'author-pays' open access seems "viable" but requires "further experimentation".

In the meantime, the report advises the government to oblige UK authors to publish articles on their institutions' websites.

Many people have questioned whether the author-pays open-access model, as pursued by the Public Library of Science and BioMed Central, for example, is economically sustainable. At the same time, the current system of 'reader-pays' has resulted in spiralling journal costs that many libraries can no longer afford. "This cannot continue," says committee chairman Ian Gibson, a Labour member of parliament.
The report gives advice on running open-access schemes more smoothly. For example, it suggests that funders include money in grants to cover author fees.

But the report also says that it is too early to tell how open access will pan out. "The author-pays model needs more work; that's why we are saying we shouldn't go into it right away. We have to look at the possibilities and perhaps have a pilot scheme for a certain length of time," says Gibson.

Most of the data used in the debate, such as the cost of publishing, come from the 'grey literature' of reports from the UKbased charity the Wellcome Trust, and from publisher statements or online debates, says Gibson. "I'm suspicious of the figures thrown around," he adds. The committee recommends that the government carries out a comprehensive independent study.

Its strongest recommendation is that the UK government should ensure that funders make it compulsory for researchers to post their papers online. "Our idea — a rabbit out of the hat - will make the university library system sit up and listen," says Gibson.

The idea of posting material online has been around for a decade, and an increasing number of institutions are building online repositories. DSpace, for example, developed at the Massachusetts Institute of Technology, aims to store the institute's entire intellectual output, including data and course materials (see Nature 420, 17-18; 2002).

Gibson says he hopes the report will make researchers aware of the issue. "The sad thing is that academics don't really care as long as they get their work published," notes Gibson. According to a recent survey by the Centre for Information Behaviour and the Evaluation of Research at City University London, $82 \%$ of working scientists say they know little or nothing about open access.

nature.com/nature/focus/accessdebate

For more news and analysis go to news@nature.com www.nature.com/news 